Article

\title{
Evaluation of Fracture Strength of Ceramics Containing Small Surface Defects Introduced by Focused Ion Beam
}

\author{
Nanako Sato ${ }^{1}$ and Koji Takahashi ${ }^{2, *}$ (iD \\ 1 Graduate School of Engineering, Yokohama National University, 79-5 Tokiwadai, \\ Hodogaya, Yokohama 240-8501, Japan; sato-nanako-nw@ynu.jp \\ 2 Faculty of Engineering, Yokohama National University, 79-5 Tokiwadai, \\ Hodogaya, Yokohama 240-8501, Japan \\ * Correspondence: takahashi-koji-ph@ynu.ac.jp; Tel.: +81-45-339-4017
}

Received: 9 February 2018; Accepted: 19 March 2018; Published: 20 March 2018

\begin{abstract}
The aim of this study was to clarify the effects of micro surface defects introduced by the focused ion beam (FIB) technique on the fracture strength of ceramics. Three-point bending tests on alumina-silicon carbide $\left(\mathrm{Al}_{2} \mathrm{O}_{3} / \mathrm{SiC}\right)$ ceramic composites containing crack-like surface defects introduced by FIB were carried out. A surface defect with $\sqrt{\text { area }}$ in the range 19 to $35 \mu \mathrm{m}$ was introduced at the center of each specimen. Test results showed that the fracture strengths of the FIB-defect specimens depended on $\sqrt{\text { area }}$. The test results were evaluated using the evaluation equation of fracture strength based on the process zone size failure criterion and the $\sqrt{\text { area }}$ parameter model. The experimental results indicate that FIB-induced defects can be used as small initial cracks for the fracture strength evaluation of ceramics. Moreover, the proposed equation was useful for the fracture strength evaluation of ceramics containing micro surface defects introduced by FIB.
\end{abstract}

Keywords: $\mathrm{Al}_{2} \mathrm{O}_{3} / \mathrm{SiC}$; focused ion beam; surface defect; fracture strength; process zone size failure criterion; $\sqrt{\text { area }}$ parameter model

\section{Introduction}

Ceramics have excellent mechanical, tribological, and thermal properties in comparison with metallic materials. However, there is a risk that failure initiates from defects due to the low fracture toughness of ceramics. Therefore, it is very important to quantitatively evaluate the influence of defects on fracture strength for maintenance management of ceramic components.

It is reported that the fracture toughness for small flaws is lower than that for large cracks. Thus, conventional linear elastic fracture mechanics (LEFM) is not applicable for predicting the fracture strength of ceramics containing small flaws [1]. Many authors have proposed various models for the relationship between defect size and fracture strength [2-6]. Ando et al. proposed the process zone size failure criterion and reported that the fracture strength of ceramics containing small surface cracks could be evaluated by this criterion [7]. This model can predict the fracture strength of a material having a semicircular crack introduced perpendicular to the tensile stress. Murakami and Endo proposed the $\sqrt{\text { area }}$ parameter model to predict the fatigue limit of metals having a surface crack with arbitrary shape [8]. Here, the $\sqrt{\text { area }}$ is the square root of the area of a surface defect projected onto the direction of the maximum tensile stress. The $\sqrt{\text { area }}$ parameter model is widely applied to evaluate the fatigue limit of metals $[9,10]$. In a previous study, we proposed a new evaluation equation for the fracture strength of ceramics combining the process zone size failure criterion and the $\sqrt{\text { area }}$ parameter model [11]. This equation is useful for the evaluation of fracture strength of ceramics having a surface crack with arbitrary shape and orientation introduced by the indentation method. 
However, it is known that tensile residual stress is generated around the indentation when a pre-crack is introduced on the surface of a ceramic material by the indentation method [12]. Therefore, elimination of the tensile residual stress by surface polishing or annealing in inert gas is necessary [13]. If the tensile residual stress is not eliminated, the influence of residual stress on the fracture strength should be considered to predict the fracture strength with high accuracy [13]. The dimensions of a defect at the origin of a fracture in an actual ceramic material are equivalent to the grain size, which is less than $20 \mu \mathrm{m}$ in a typical ceramic. However, the dimensions of defects introduced in most of the previous studies were larger than $20 \mu \mathrm{m}$ because it is difficult to introduce small surface cracks by the indentation method [14-16].

In this study, we introduced crack-like surface defects on the surface of ceramics by the focused ion beam (FIB) technique. The FIB technique is a high-precision working method that uses the effect of sputtering by ion beam scanning on the surface of a material. Sakamoto et al. reported that the fatigue limits of FIB-notched specimens were equivalent to the fatigue limits of annealed fatigue-cracked specimens of carbon steel [17]. Rokio and Solin evaluated small crack initiation and propagation from small FIB-defect in high strength steel and reported that a FIB notch to initiate small cracks is a useful way to test small crack growth in high strength steels [18]. However, to our knowledge, the influence of FIB-introduced surface defects on the fracture strength of ceramics has not yet been studied. In this paper, the effects of microscopic surface defects introduced by FIB on the fracture strength of an $\mathrm{Al}_{2} \mathrm{O}_{3} / \mathrm{SiC}$ composite are clarified. Regarding the relationship between fracture strength and defect size, the consistencies of the test results and the values predicted by the proposed evaluation equation were verified.

\section{Evaluation Equation of Fracture Strength}

In this section, an outline of the proposed equation for fracture strength evaluation is described [11]. The equation is based on the process zone size failure criterion [7] and the $\sqrt{\text { area }}$ parameter model $[8,19]$.

Ando et al. proposed the following equation to predict the fracture strength $\left(\sigma_{\mathrm{C}}\right)$ of ceramics with a small surface crack focusing on the process zone size at the crack tip and [7]

$$
\frac{\pi}{8}\left(\frac{K_{\mathrm{IC}}}{\sigma_{0}}\right)^{2}=a_{e}\left\{\sec \left(\frac{\pi \sigma_{C}}{2 \sigma_{0}}\right)-1\right\}
$$

where $K_{\mathrm{IC}}\left(\mathrm{MPa} \cdot \mathrm{m}^{1 / 2}\right)$ is the fracture toughness, and $\sigma_{0}(\mathrm{MPa})$ is the fracture strength of a smooth specimen assuming a defect is sufficiently small, and $\sigma_{\mathrm{C}}(\mathrm{MPa})$ is the fracture strength of a specimen containing a surface crack. The equivalent crack length, $a_{\mathrm{e}}(\mu \mathrm{m})$ is defined as

$$
a_{e}=\frac{1}{\pi}\left(\frac{K_{\mathrm{IC}}}{\sigma_{c}}\right)^{2}
$$

On the other hand, Murakami showed that the maximum stress intensity factor $\left(K_{\max }\right)$ at the edge of a surface crack with arbitrary shape under tensile stress $\left(\sigma_{\infty}\right)$ could be approximated within $10 \%$ error by [19]

$$
K_{\max } \cong 0.650 \sigma_{\infty} \sqrt{\pi \sqrt{\text { area }}},
$$

where $\sqrt{\text { area }}$ is the square root of the area of a surface defect projected onto the direction of the maximum tensile stress. When $\sigma_{\mathrm{C}}$ is applied to a surface crack, the $K_{\max }$ value reaches $K_{\mathrm{IC}}$. Equation (3) leads to

$$
K_{\mathrm{IC}}=0.650 \sigma_{\mathrm{C}} \sqrt{\pi \sqrt{\text { area }}} .
$$


The relationship between fracture strength $\sigma_{\mathrm{C}}$ and the crack size $\sqrt{\text { area }}$ is expressed as follows based on Equations (1), (2) and (4)

$$
\sigma_{C}=\cos ^{-1}\left(\frac{3.38 \sigma_{0}^{2} \sqrt{\text { area }}}{\pi \cdot K_{\mathrm{IC}^{2}}+3.38 \sigma_{0}^{2} \sqrt{\text { area }}}\right) \cdot \frac{2 \sigma_{0}}{\pi} .
$$

This is the equation to evaluate the fracture strength of a ceramic material containing a surface defect with arbitrary shape. Figure 1 shows the relationship between $\sigma_{\mathrm{C}}$ and $\sqrt{\text { area }}$ of alumina reinforced by silicon carbide $\left(\mathrm{Al}_{2} \mathrm{O}_{3} / \mathrm{SiC}\right)$ [11]. The dotted line indicates the $\sigma_{\mathrm{C}}$ predicted based on conventional LEFM. The predicted values of $\sigma_{C}$ based on LEFM are overestimate for $\sqrt{\text { area }}$ less than $20 \mu \mathrm{m}$. Thus, conventional LEFM is not applicable to ceramics with small cracks. On the other hand, the solid line indicates the $\sigma_{\mathrm{C}}$ predicted based on Equation (5). Although the $\sigma_{\mathrm{C}}$ predicted based on Equation (5) were slightly smaller than those of the experimental results, they agreed relatively well with the experimental results in the range of 5-20 $\mu \mathrm{m}$. In this study, the relationship between $\sqrt{\text { area }}$ of an FIB defect and fracture strength was evaluated using $K_{\mathrm{IC}}$ and $\sigma_{0}$ as the basic mechanical properties of the sample material.

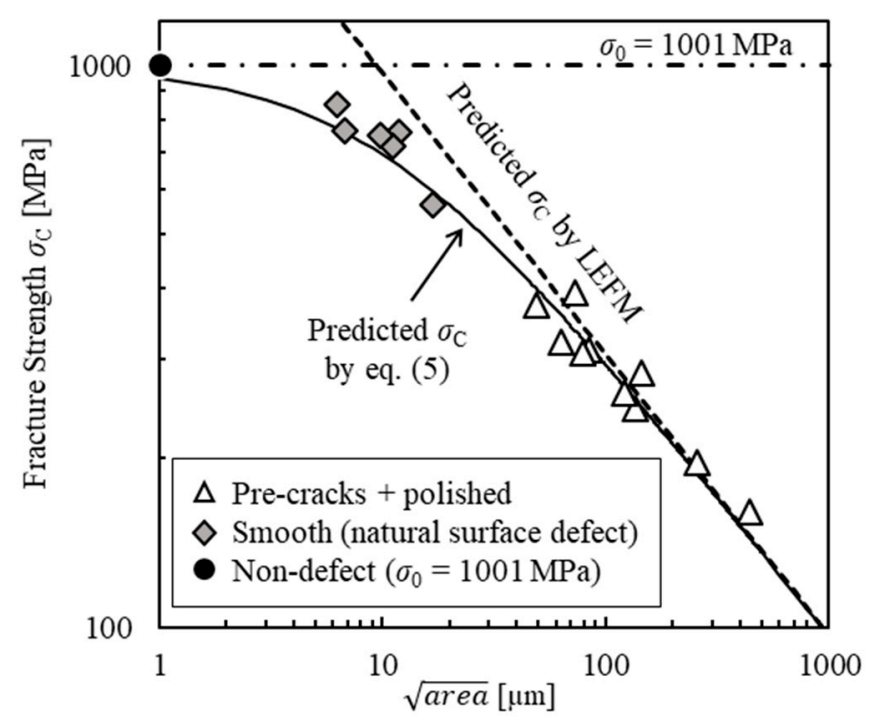

Figure 1. Relationship between fracture strength and $\sqrt{\text { area }}$ of $\mathrm{Al}_{2} \mathrm{O}_{3} / \mathrm{SiC}$ [11].

\section{Experimental Procedures}

\subsection{Test Specimen}

Alumina reinforced by silicon carbide $\left(\mathrm{Al}_{2} \mathrm{O}_{3} / \mathrm{SiC}\right)$ was selected as a test material in this study. The $\mathrm{Al}_{2} \mathrm{O}_{3}$ powder (AKP-50, Sumitomo Chemical Industry Co. Ltd., Tokyo, Japan) used in this study had a mean particle size of $0.2 \mu \mathrm{m}$. The SiC powder (ultrafine grade, Ibiden Co. Ltd., Gifu, Japan) used had a mean particle size of $0.27 \mu \mathrm{m}$. The samples were prepared using a mixture of $\mathrm{Al}_{2} \mathrm{O}_{3}$ with $15 \mathrm{vol} \%$ $\mathrm{SiC}$ powder. To this mixture, isopropanol was added, and the mixture was blended thoroughly for $24 \mathrm{~h}$ by ball milling. After drying and comminution, the mixture was hot-pressed at $1973 \mathrm{~K}$ and $35 \mathrm{MPa}$ for $2 \mathrm{~h}$ in an $\mathrm{N}_{2}$ atmosphere [20]. The hot-pressed plates were cut into bending test specimens measuring $3 \times 4 \times 20 \mathrm{~mm}$. The surface of each specimen was polished to a mirror-like finish.

\subsection{Specimen Preparations}

To heal surface cracks induced during machining, all the bending test specimens were heat-treated at $1573 \mathrm{~K}$ for $1 \mathrm{~h}$ in air, which are the optimum healing conditions for surface cracks in $\mathrm{Al}_{2} \mathrm{O}_{3} / \mathrm{SiC}$ [20]. 
These specimens are called "smooth" specimens. The $\sigma_{0}$ value was evaluated by the strength distribution of the smooth specimens.

An FIB defect was introduced at the center of each smooth specimen by using a multi beam SEM-FIB system JIB-4501 (by JEOL Ltd., Tokyo, Japan). These specimens are called the "FIB-defect" specimens. Figure 2 shows the detail of the FIB technique process. A test specimen was fixed on a jig with carbon tape. The FIB defect was processed while monitoring the processing state using the SEM. Figure 3a schematically shows the shape of an FIB defect. The surface lengths (2c) ranged from 20 to $60 \mu \mathrm{m}$ and the depths $(d)$ ranged from 19 to $24 \mu \mathrm{m}$. The conditions of the FIB technique are presented in Table 1 . The area of a defect was evaluated based on the fracture surface observation.

For comparison, "pre-crack + polished" specimens were prepared in the following procedure. First, a Knoop indentation was made at the center of each smooth specimen. Figure $3 \mathrm{~b}$ shows the shape of a Knoop pre-crack. The indentation loads ranged from 9.8 to $49 \mathrm{~N}$. Next, these specimens were polished using a 1- $\mu \mathrm{m}$ diamond slurry to eliminate the tensile residual stress around the indentations. The amount of material removed from the surface was 4 to 6 times the indentation depth. The ASTM standard C1421 suggests removing 4.5 to 5 times the indentation depth [21]. Thus, the removed depth in this study almost met the standard.

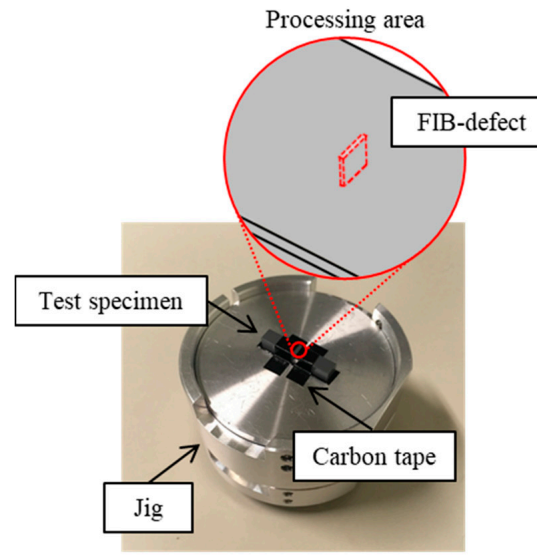

(a)

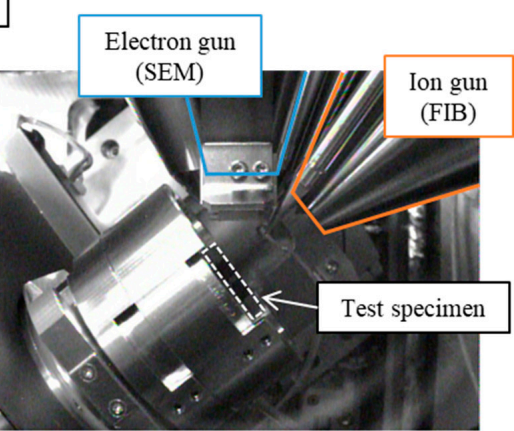

(b)

Figure 2. Photographs of the FIB process: (a) fixing method of test specimen; (b) inside of device.

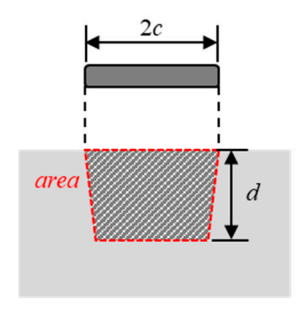

(a) FIB-defect

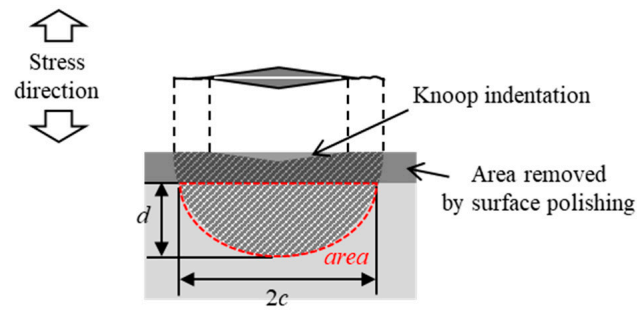

(b) Knoop pre-crack

Figure 3. Schematic illustrations of surface defects: (a) FIB-defect specimen; (b) pre-crack + polished specimen.

Table 1. FIB processing conditions.

\begin{tabular}{cc}
\hline Ion Source & Ga Liquid Metal Ions \\
\hline Accelerating voltage & $30 \mathrm{kV}$ \\
Prove current & $3000 \mathrm{pA}$ \\
Dose & $190-280 \mathrm{nC} / \mu \mathrm{m}^{2}$ \\
\hline
\end{tabular}




\subsection{Measurement of Fracture Toughness}

The fracture toughness $K_{\text {IC }}$ value was evaluated by the indentation fracture (IF) method. Vickers indentations were made on the polished surface of a bending test specimen by the application of an indentation load of $49 \mathrm{~N}$ for $15 \mathrm{~s}$. Then, $K_{\mathrm{IC}}\left(\mathrm{Pa} \cdot \mathrm{m}^{1 / 2}\right)$ was calculated using the following equation in accordance with the Japan Industrial Standards [22]

$$
K_{\mathrm{IC}}=0.026 \frac{E^{\frac{1}{2}} P^{\frac{1}{2}} a}{c^{\frac{3}{2}}}
$$

where $E(\mathrm{~Pa})$ is the Young's modulus, $P(\mathrm{~N})$ is the indentation load, $a(\mathrm{~m})$ is half the diagonal length of the indentation, and $c(\mathrm{~m})$ is half the surface crack length. The units of calculated values of $K_{\mathrm{IC}}$ were converted into "MPa. $\mathrm{m}^{1 / 2}$ ". Crack length was measured using an optical microscope with total magnifications of $580 \times$ and higher to avoid the measurement error of $K_{\text {IC }}$ values [23].

\subsection{Measurement of Fracture Strength}

The $\sigma_{\mathrm{C}}$ values of each specimen were measured by a three-point bending test, as shown in Figure 4, at room temperature in air. The span length was $16 \mathrm{~mm}$, and the crosshead speed was $0.5 \mathrm{~mm} / \mathrm{min}$. After the bending test, the fracture surfaces were observed by laser microscopy, and the size of the defects at the fracture origins was measured.
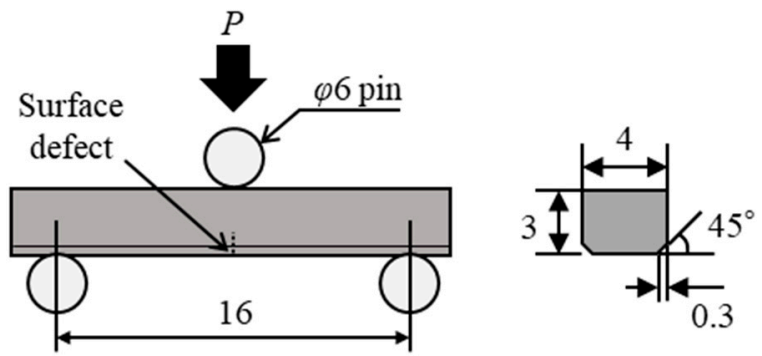

Unit : $\mathrm{mm}$

Figure 4. Schematic diagram of the three-point loading system and size and dimensions of test specimen.

\section{Results and Evaluation of Fracture Strength}

\subsection{Mechanical Properties of the Sample Material}

In this section, the calculated results of $K_{\mathrm{IC}}$ and $\sigma_{0}$ are presented. An average and a standard deviation of the $K_{\mathrm{IC}}$ value of four samples measured by the IF method were $3.50 \pm 0.05 \mathrm{MPa} \cdot \mathrm{m}^{1 / 2}$. The scatter of the $K_{\mathrm{IC}}$ value is quite small.

The $\sigma_{0}$ value of the sample material was estimated using the strength distribution of the smooth specimens. The two-parameter Weibull function is expressed by

$$
F\left(\sigma_{C}\right)=1-\exp \left\{-\left(\frac{\sigma_{C}}{\beta}\right)^{\alpha}\right\}
$$

where $F\left(\sigma_{\mathrm{C}}\right)$ is the cumulative failure probability based on the median rank method, $\alpha$ is the scale parameter, and $\beta$ is the shape parameter. Figure 5 shows the two-parameter Weibull distribution of the smooth specimens. The test results were plotted as the relationship between $\ln \left(\sigma_{\mathrm{C}}\right)$ and $\ln \left\{\ln (1 /(1-F)\}\right.$ led by Equation (7). The second horizontal and vertical axis show $\sigma_{\mathrm{C}}$ and $F$ values, respectively. Two parameters were determined using the maximum likelihood method based on JIS R1625 [24]. The $\alpha$ value was 8.81, and the $\beta$ value was $871 \mathrm{MPa}$. In Figure 5, a thick solid line and thin solid lines show the approximation line and the $90 \%$ confidence interval, respectively. The $90 \%$ 
confidence interval values of $\alpha$ and $\beta$ are $\left(\alpha_{\mathrm{L}}, \alpha_{\mathrm{U}}\right)=(6.72,11.6),\left(\beta_{\mathrm{L}}, \beta_{\mathrm{U}}\right)=(838,910)$. In the Weibull distribution, the $F\left(\sigma_{\mathrm{C}}\right)$ value increased as the defect dimensions in the specimens decreased. Because the size of defects in a smooth the specimen with $F\left(\sigma_{\mathrm{C}}\right)=99 \%$ considered to be sufficiently small, the $\sigma_{\mathrm{C}}$ value at $F\left(\sigma_{\mathrm{C}}\right)=99 \%$ is regarded as $\sigma_{0}$. This evaluation method of $\sigma_{0}$ showed a good estimation results of $\sigma_{\mathrm{C}}$ as shown in Figure 1 [11]. Substituting the values of $\alpha$ and $\beta$ of the smooth specimen and $F\left(\sigma_{\mathrm{C}}\right)=99 \%$ in Equation $(7), \sigma_{0}=1036 \mathrm{MPa}$ was calculated.

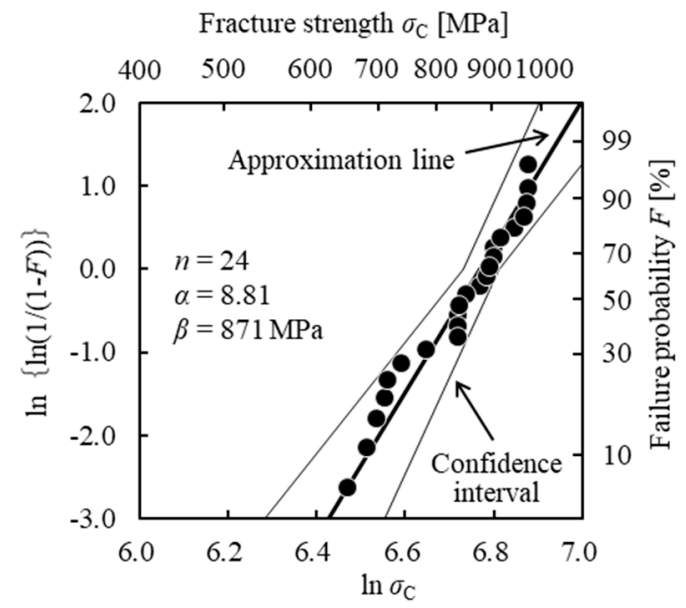

Figure 5. Two-parameter Weibull distribution of fracture strength of the smooth specimens.

\subsection{Fracture Strength of FIB-Defect Specimens}

All specimens containing FIB-induced surface defects fractured at the FIB-defect area as a result of the three-point bending tests. Figure $6 \mathrm{a}, \mathrm{b}$ show laser microscope images of fractured surfaces of a FIB-defect specimen and a pre-crack + polished specimen, respectively. The surface length $2 c$, the depth $d$, and the $\sqrt{\text { area }}$ of the FIB-defects and pre-cracks after polishing were measured by these observations. Table 2 shows the results of the bending tests for the FIB-defect specimens and the pre-crack + polished specimens. The sizes of the FIB defects were in the following range: $\sqrt{\text { area }}=19-35 \mu \mathrm{m}$. The $\sigma_{\mathrm{C}}$ value of the FIB-defect specimens decreased with increasing $\sqrt{\text { area }}$. Similar to the pre-crack + polished specimens, $\sigma_{\mathrm{C}}$ showed strong $\sqrt{\text { area }}$-dependency in the FIB-defect specimens.

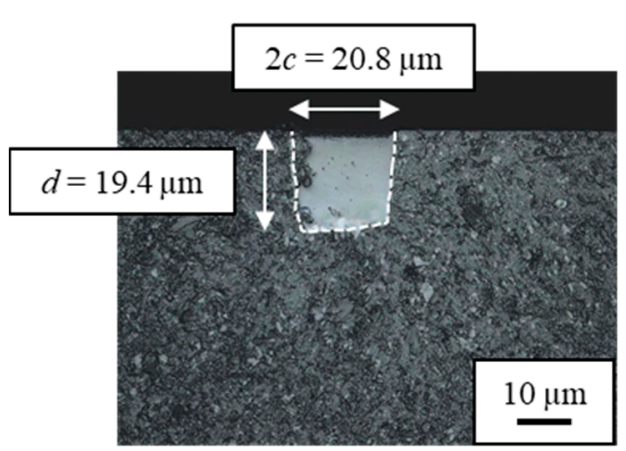

(a) FIB-defect

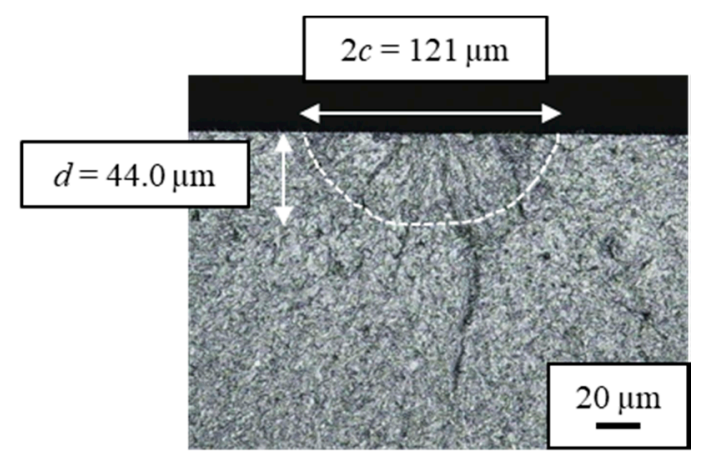

(b) Pre-crack + polished

Figure 6. Laser microscope images of fracture surfaces: (a) FIB-defect specimen, $\sqrt{\text { area }}=19.1 \mu \mathrm{m}$, $\sigma_{\mathrm{C}}=687 \mathrm{MPa} ;(\mathbf{b})$ pre-crack + polished specimen, $\sqrt{\text { area }}=64.6 \mu \mathrm{m}, \sigma_{\mathrm{C}}=400 \mathrm{MPa}$. 
Table 2. Bending test results.

\begin{tabular}{ccccc}
\hline Type of Defect & $\begin{array}{c}\text { Surface Length } 2 c \\
(\mu \mathrm{m})\end{array}$ & Depth $\boldsymbol{d}(\boldsymbol{\mu \mathrm { m } )})$ & $\sqrt{\text { area }}(\boldsymbol{\mu m})$ & $\begin{array}{c}\text { Fracture Strength } \\
\sigma_{\mathbf{C}}(\mathbf{M p a})\end{array}$ \\
\hline & 20.8 & 19.4 & 19.1 & 687 \\
FIB-defect test & 20.0 & 23.2 & 20.4 & 715 \\
specimen & 33.4 & 21.1 & 25.3 & 597 \\
& 32.3 & 22.5 & 26.2 & 557 \\
& 32.8 & 23.8 & 27.4 & 592 \\
Pre-crack + & 46.2 & 24.1 & 32.6 & 530 \\
polished test & 60.1 & 21.3 & 35.2 & 508 \\
specimen & 121 & 44.0 & 64.6 & 400 \\
& 124 & 47.5 & 68.0 & 322 \\
\hline
\end{tabular}

\subsection{Comparison Between Predicted Fracture Strength and Test Results}

The $\sigma_{\mathrm{C}}$ of the sample material was predicted substituting $K_{\mathrm{IC}}=3.50 \mathrm{MPa} \cdot \mathrm{m}^{1 / 2}$ and $\sigma_{0}=1036 \mathrm{MPa}$ into Equation (5). Figure 7 shows the predicted $\sigma_{C}$ values and the bending test results. For the pre-crack + polished specimens, the predicted $\sigma_{\mathrm{C}}$ values matched the experimental results. Thus, the usefulness of this equation was confirmed. The errors between the experimental and predicted results were generally within $\pm 15 \%$. It is thought that the prediction errors are mainly caused by the approximation errors of $K_{\max }$ by Equation (3). For the FIB-defect specimens, the experimental $\sigma_{\mathrm{C}}$ are between the predicted $\sigma_{\mathrm{C}}$ based on LEFM and Equation (5). The predicted values of $\sigma_{\mathrm{C}}$ based on LEFM and Equation (5) give the upper and lower limit, respectively. Similar tendency that Equation (5) gives lower $\sigma_{\mathrm{C}}$ was observed in the results shown in Figure 1. The results indicate that a FIB-defect can be used as a small initial crack for fracture strength evaluation of ceramics. It was found that the evaluation equation was useful for evaluating the fracture strengths of ceramics containing micro surface defects introduced by FIB.

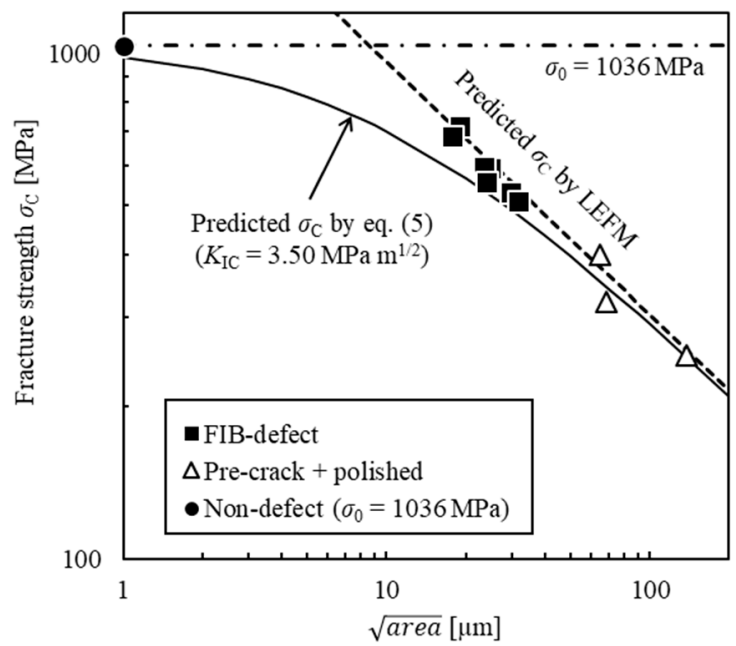

Figure 7. Comparison between the predicted fracture strength and the bending test results.

\section{Conclusions}

This study investigated the fracture strengths of $\mathrm{Al}_{2} \mathrm{O}_{3} / \mathrm{SiC}$ samples in which micro surface defects had been introduced by the FIB technique. The test results were evaluated using the proposed evaluation equation of fracture strength. The results are summarized as follows: 
(1) The micro surface defects in the size range of $\sqrt{\text { area }}=19-35 \mu \mathrm{m}$ were introduced on the surface of $\mathrm{Al}_{2} \mathrm{O}_{3} / \mathrm{SiC}$ by the FIB technique.

(2) The fracture strengths of the FIB-defect specimens showed $\sqrt{\text { area }}$ dependency. This result is similar to that obtained for the pre-crack + polished specimens.

(3) FIB-defect can be used as a small initial crack for fracture strength evaluation of ceramics.

(4) The fracture strengths of the FIB-defect specimens predicted by the evaluation equation matched the test results. It was confirmed that the proposed equation for fracture strength evaluation was useful for ceramics containing micro surface defects introduced by FIB.

Acknowledgments: This study was supported in part by a grant for Scientific Research (B) (16H04231) from the Ministry of Education, Culture, Sports, Science, and Technology of Japan.

Author Contributions: N. Sato and K. Takahashi conceived and designed the experiments; N. Sato performed the experiments and evaluated the data; N. Sato and K. Takahashi wrote the paper.

Conflicts of Interest: The authors declare no conflict of interest.

\section{References}

1. Usami, S.; Kimoto, H.; Takahashi, I.; Shida, S. Strength of ceramic materials containing small flaws. Eng. Fract. Mech. 1986, 23, 745-761. [CrossRef]

2. Hoshide, T. Grain fracture model and its application to strength evaluation in engineering ceramics. Eng. Fract. Mech. 1993, 44, 403-408.

3. Li, C.W.; Lui, S.C.; Goldacker, J. Relation between strength, microstructure, and grain-Bridging characteristics in in situ reinforced silicon nitride. J. Am. Ceram. Soc. 1995, 78, 449-459. [CrossRef]

4. Taylor, D. Predicting the fracture strength of ceramic materials using the theory of critical distances. Eng. Fract. Mech. 2004, 71, 2407-2416. [CrossRef]

5. Munz, D. What can we learn from R-curve measurements? J. Am. Ceram. Soc. 2007, 90, 1-15. [CrossRef]

6. Askes, H.; Susmel, L. Understanding cracked materials: Is linear elastic fracture mechanics obsolete? Fatigue Fract. Eng. Mater. Struct. 2015, 38, 154-160. [CrossRef]

7. Ando, K.; Kim, B.A.; Iwasa, M.; Ogura, N. Process zone size failure criterion and probabilistic fracture assessment curves for ceramics. Fatigue Fract. Eng. Mater. Struct. 1992, 15, 139-149. [CrossRef]

8. Murakami, Y.; Endo, M. Quantitative evaluation of fatigue strength of metals containing various small defects or cracks. Eng. Fract. Mech. 1983, 17, 1-15.

9. Saberifar, S.; Mashreghi, A.R.; Mosalaeepur, M.; Ghasemi, S.S. The interaction between non-metallic inclusions and surface roughness in fatigue failure and their influence on fatigue strength. Mater. Des. 2012, 35, 720-724. [CrossRef]

10. Beretta, S.; Romano, S. A comparison of fatigue strength sensitivity to defects for materials manufactured by AM or traditional processes. Int. J. Fatigue 2017, 94, 178-191. [CrossRef]

11. Sato, N.; Takahashi, K. Prediction of fracture strength for ceramics containing a surface defect with arbitrary shape. Trans. Jpn. Soc. Spring Eng. 2018, 63. in press.

12. Marshall, D.B.; Lawn, B.R. Residual stress effects in sharp contact cracking: Indentation fracture mechanics. J. Mater. Sci. 1979, 14, 2001-2012. [CrossRef]

13. Chou, I.A.; Chan, H.M.; Harmer, M.P. Effect of Annealing Environment on the Crack Healing and Mechanical Behavior of Silicon Carbide-Reinforced Alumina Nanocomposites. J. Am. Ceram. Soc. 1998, 81, 1203-1208. [CrossRef]

14. Li, Z.; Ghosh, A.; Kobayashi, A.; Bradt, R.C. Indentation fracture toughness of sintered silicon carbide in the Palmquist crack regime. J. Am. Ceram. Soc. 1989, 72, 904-911. [CrossRef]

15. Takahashi, K.; Iwanaka, K.; Osada, T.; Koike, H. Increase in strength of partially stabilized zirconia after shot peening. J. Mater. Eng. Perform. 2015, 24, 3573-3578. [CrossRef]

16. Ćorić, D.; Renjo, M.M.; Ćurković, L. Vickers indentation fracture toughness of Y-TZP dental ceramics. Int. J. Refract. Met. Hard Mater. 2017, 64, 14-19. [CrossRef] 
17. Sakamoto, J.; Takahashi, Y.; Aono, Y.; Noguchi, H. Method for Assessing Applicability of an Artificial Flaw as a Small initial crack for fatigue limit evaluation and its application to a drill Hole and an FIB processed sharp notch in annealed $0.45 \%$ carbon steel. J. Test. Eval. 2013, 41, 194-199. [CrossRef]

18. Roiko, A.; Solin, J. Measurement of small cracks initiating from inclusions, Focused Ion Beam notches and drilled holes. Int. J. Fatigue 2014, 62, 154-158. [CrossRef]

19. Murakami, Y. Analysis of stress intensity factors of modes I, II and III for inclined surface cracks of arbitrary shape. Eng. Fract. Mech. 1985, 22, 101-114. [CrossRef]

20. Osada, T.; Nakao, W.; Takahashi, K.; Ando, K.; Saito, S. Kinetics of Self-crack-healing of alumina/Silicon carbide composite including oxygen partial pressure effect. J. Am. Ceram. Soc. 2009, 92, 864-869. [CrossRef]

21. ASTM International. Standard Test Methods for Determination of Fracture Toughness of Advanced Ceramics at Ambient Temperature; ASTM C1421-10; ASTM International: West Conshohocken, PA, USA, 2010.

22. Japanese Standards Association. Testing Methods for Fracture Toughness of Fine Ceramics at Room Temperature; JIS R1607; Japanese Standards Association: Tokyo, Japan, 2015.

23. Miyazaki, H.; Yoshizawa, Y. Correlation of the indentation fracture resistance measured using high-resolution optics and the fracture toughness obtained by the single edge-notched beam (SEPB) method for typical structural ceramics with various microstructures. Ceram. Int. 2016, 42, 7873-7876. [CrossRef]

24. Japanese Standards Association. Weibull Statics of Strength Data for Fine Ceramics; JIS R1607; Japanese Standards Association: Tokyo, Japan, 2010.

(C) 2018 by the authors. Licensee MDPI, Basel, Switzerland. This article is an open access article distributed under the terms and conditions of the Creative Commons Attribution (CC BY) license (http:/ / creativecommons.org/licenses/by/4.0/). 